\title{
A comparison of two delay of reward procedures, pre-reinforcement delay vs post-reinforcement delay'
}

\author{
E. J. CAPALDI, R. C. GODBOUT, and C. KSIR, University of \\ Texas, Austin, Texas 78712
}

The effects on performance of $50 \%$ prereinforcement delay of reward were compared with those of $50 \%$ postreinforcement delay of reward. This comparison was made employing two different schedules of reward. Under one of these schedules, predelay and postdelay produced greater resistance to extinction than immediate reward. However, under the second reward schedule, the effects of predelay and postdelay differed greatly. While the postdelay group was about as resistant to extinction as the immediately rewarded control group, the predelay group was less resistant to extinction.

After entering the goalbox, $\mathrm{S}$ may receive one of two kinds of delay of reward. The better-known delay procedure is to deliver the reward only after $S$ has been detained in the goalbox (prereinforcement delay). Another procedure is to deliver the reward immediately, detaining $S$ after the reward has been consumed (postreinforcement delay). Increasing attention has been given to postdelay. The most notable finding has been that postdelay on all trials increases resistance to extinction (Fehrer, 1956; McCain \& Bowen, 1967; Mikulka, Vogel, \& Spear, 1967).

Fehrer (1956) has compared predelay with postdelay. In that study delay was given on all trials ( $100 \%$ delay). A major interest of this investigation was to compare $50 \%$ postdelay with $50 \%$ predelay. Under predelay the schedule of delayed trials and immediately rewarded trials has been shown to be a potent variable. It has been shown that resistance to extinction is increased if predelay trials precede immediate trials, but not vice versa (e.g., Capaldi \& Poynor, 1966; Wike, Kintsch, \& Gutekunst, 1959). Accordingly, in comparing 50\% predelay with $50 \%$ postdelay, it seemed advisable to employ at least two different schdules of reward. This provides greater generality, for we not only compare $50 \%$ predelay with $50 \%$ postdelay, but do so as a function of schedule of reward.

\section{METHOD}

The Ss were 50 male Holtzman rats about 110 days of age. There were five groups of $10 \mathrm{Ss}$ each. Following seven days on a 12-g deprivation cycle, the initial two squads of five $\mathrm{Ss}$, a squad consisting of one $S$ from each group, were allowed to explore the alley individually for $10 \mathrm{~min}$. On the following day two additional squads were given alley exploration and so on. On the succeeding five days of pretraining Ss were allowed to eat $.045 \mathrm{~g}$ Noyes pellets from the goalcup. On Day 7 of pretraining each $\mathrm{S}$ was given two running trials in the alley, the reward being six pellets. The alley was the same as that employed in the immediately previous study by Capaldi, Godbout, \& Downs (in press).

There were 12 days of acquisition training at two trials each day. The Ss in a squad were run in rotation, the rotation order being changed daily. The intertrial interval averaged between 8 and $10 \mathrm{~min}$. Group II received two immediately rewarded trials daily (six pellets reward). The predelay and postdelay groups constituted a 2 by 2 factorial. Either the initial daily trial was delayed reward, the second daily trial being rewarded immediately (DI) or vice versa (ID). For the predelay DI and ID groups, the reward on delay trials was delivered $30 \mathrm{sec}$ after $S$ entered the goalbox. For the postdelay DI and ID groups, reward was delivered immediately on every trial. On delay trials, however, the $\mathrm{S}$ was detained in the goalbox for $30 \mathrm{sec}$ after having eaten the six-pellet reward. The postdelay was estimated by confining $S$ in the goalbox for $35 \mathrm{sec}$, since $5 \mathrm{sec}$ was the estimated time for eating six pellets.

Following acquisition training Ss were given 12 extinction trials, all 12 trials being given on the day following the last day of acquisition training. The intertrial interval, etc., remained the same as in acquisition, the only difference being that $S$ was not rewarded. The $S$ was confined for $30 \mathrm{sec}$ on nonrewarded trials. On all trials $S$ was allowed $180 \mathrm{sec}$ to enter the goalbox. When $180 \mathrm{sec}$ elapsed, $S$ was placed in the goalbox and assigned a $60 \mathrm{sec}$ time for each alley section.

\section{RESULTS}

All times for the start, run, and goal sections were converted to speeds (1/time), and a total speed measure was obtained by reciprocating the sum of a S's start, run, and goal times on a particular trial. The basic statistical analysis was a 2 by 2 factorial with the II group included, i.e., the error mean square was based on all five groups. On the last day of acquisition the groups failed to differ significantly in any of the alley sections. However, there was a significant difference in total speed between the four delay groups and the II group $(F=6.41$, $\mathrm{df}=1 / 45, \mathrm{p}<.05$ ). A Duncan's range test indicated that this difference was occasioned by the relatively slow running of the predelay ID group. Converting the raw speeds to rate measures in extinction in order to compensate for acquisition differences was later found to be unnecessary; raw speeds and rates yielded similar results.

Figure 1 shows the mean total speeds for each group on each trial of extinction. The relationships shown in Fig. 1 are typical of those which occurred in each of the alley sections Figure 1 shows that the DI groups (pre- and post-) were more resistant to extinction than the II or consistent group. While the postdelay ID group was about as resistant to extinction as Group II, the predelay ID group was clearly less resistant to extinction than Group II. The 2 by 2 factorial analysis using speeds indicated that the effects of transitions were significant in all alley sections, i.e., DI produced greater resistance to extinction than ID (start $F=13.23, p<.001$, run $F=21.85$, $p<.001$, goal $F=13.47, p<.001$ and total $F=24.86$,

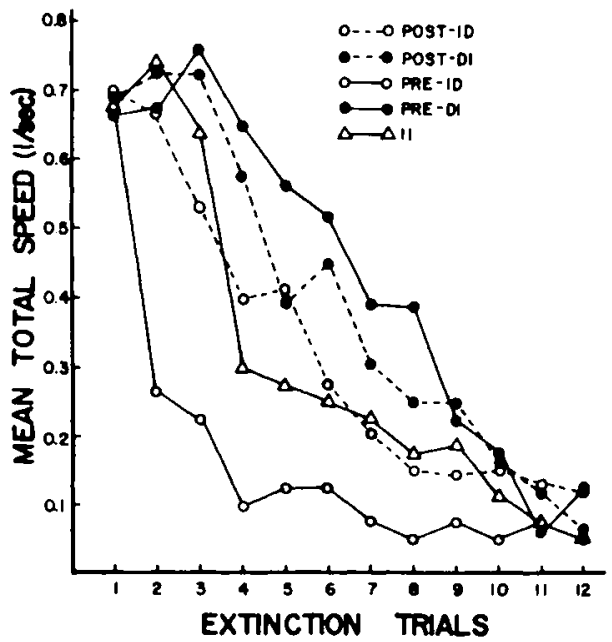

Fig. 1. Mean total speeds for each of the five experimental groups on each of the 12 extinction trials. 
$p<.001$, df $=1 / 45$ in all cases). The interaction between transitions and type of delay was significant in the run section $(F=6.47, p<.05)$ and for total speed $(F=9.55, p<.01)$. This interaction suggests that differences between DI and ID were greater for predelay than for postdelay, which is clearly evident in Fig. 1.

Subsequent Duncan's range tests for total speed indicated that (a) both of the DI groups were more resistant to extinction than Group II $(p<.05)$, (b) that Group II did not differ from the postdelay ID group and (c) that the predelay ID group was less resistant to extinction than Group II $(\mathrm{p}<.01)$.

\section{DISCUSSION}

The results suggest that in comparing $50 \%$ predelay with $50 \%$ postdelay, it is necessary to consider schedule of reward. If the schedule contains DI transitions, then both predelay and postdelay will increase resistance to extinction. While this increase seemed greater under predelay than under postdelay, the difference was not significant here. The results for ID transitions were different from those for DI transitions. First of all, in acquisition the ID predelay group was relatively slow. In extinction the predelay ID group was less resistant to extinction than either the II group or the ID postdelay group.

Several comments are in order in comparing the present results with previous results in the literature. As previously indicated. it has already been shown that DI transitions are necessary to increase resistance to extinction under postdelay. As previously cited, $100 \%$ postdelay increases resistance to extinction. Note, however, that under $100 \%$ postdelay DI transitions occur. That is, under $100 \%$ postdelay the $\mathrm{S}$ is rewarded immediately on every trial, thus immediate reward always follows a postdelay trial.

In relating the results for the predelay ID group to previous findings in the literature, it is necessary to consider initially several generalities. According to the sequential lyypothesis (e.g.. Capaldi, 1967) each kind of transition has a different effect on performance (i.e.. DI, ID, DD, and II). Performance under any particular reward schedule is the resultant or outcome of the effects of each kind of transition acting separately. This in mind, consider that the present predelay ID group was less resistant to extinction that the II control. In a previous investigation (Wike et al, 1959) it was found that a predelay ID group was about as resistant to extinction as the consistently rewarded control. But in that investigation, unlike here, the predelay ID group also received transitions from I trials to I trials. e.g.. IID. Presumably, then, the present results reflect the influence of ID transitions in relatively "pure" form, i.e., in the absence of the complicating effects of II transitions. It appears that when II transitions are present they obscure the fact that predelay ID transitions actually reduce resistance to extinction.

Leonard (in press) has recently presented data which suggest that, in partial reward, transitions from rewarded trials (I) to nonrewarded trials $(\mathrm{N})$ actually decreased resistance to extinction. The amount of reduction increased as magnitude of reward increased. Leonard's results for IN transitions are, of course, consistent with the present results for ID transitions. According to the present model, partial reward (or delayed reward) both decreases resistance to extinction (IN transitions) and increases resistance to extinction (NI transitions). A partial group (or delay group) is more resistant to extinction than a consistently rewarded control group because the increasing effect on extinction of NI transitions is greater than the decreasing effect on extinction of IN transitions. Increased resistance to extinction under partial reward or partial delay of reward is, then, a behavioral outcome of several processes acting both independently and sometimes in opposite ways. A theoretical model for IN and NI transitions (or ID and DI) has been presented elsewhere (Capaldi, 1967).

\section{REFERENCES}

CAPALDI, E. J. A sequential hypothesis of instrumental learning. In $\mathrm{K}$. W. Spence and J. T. Spence (Eds.), The psychology of learning and motivation: Advances in research and theory. Vol. 1. New York: Academic Press, Inc., 1967. Pp. 67-156.

CAPALDI, E. J., GODBOUT, R. C., \& DOWNS, B. Joint effects of magnitude of immediate reward and magnitude of delayed reward on acquisition and extinction. Psychonomic Science, in press.

CAPALDI, E. J., \& POYNOR, H. Aftereffects and delay of reward. Journal of Experimental Psychology, 1966, 71, 80-88.

FEHRER, E. Effects of amount of reinforcement and of pre- and postreinforcement delays on learning and extinction. Journal of Experimental Psychology. 1956, 52,167-176.

LEONARD, D. W. Amount and sequence of reward in partial and continuous reinforcement. Journal of Comparative \& Physiological Psychology, in press.

MCCAIN, G., \& BOWEN, J. Pre- and postreinforcement delay with a small number of acquisition trials. Psychonomic Science, 1967, 7, $121-122$.

MIKULKA, P. J., VOGEL, J. R., \& SPEAR, N. F. Postconsummatory delay and goal box confinement. Psychonomic Science, 1967, 9 381-382.

WIKE, E. L., KINTSCH, W., \& GUTEKUNST, R. Patterning effects in partially delayed reinforcement. Journal of Comparative \& Physiological Psychology, 1959, 52, 411.414.

NOTE

1. This research was supported in part by National Institute of Child Health and Human Development Research Grant HD00949-06 to the first author and by Public Health Service Fellowship 2-F1-MH-32, 183-03 (PS) from the National Institute of Mental Health to the second author. 